\title{
Juvenile open-angle Glaucoma associated with Leber's hereditary optic neuropathy: a case report and literature review
}

\author{
Yun-Hsuan Lin ${ }^{1}$, Nan-Kai Wang ${ }^{2,3}$, Ling Yeung ${ }^{1,3}$, Chi-Chun Lai ${ }^{2,3}$ and Lan-Hsin Chuang ${ }^{1,3^{*}}$ (D)
}

\begin{abstract}
Background: Leber's hereditary optic neuropathy (LHON) is a maternally inherited recessive disease rarely complicated with glaucoma. We conducted a clinical and genetic retrospective case series to describe three cases of juvenile open-angle glaucoma (JOAG) and an ND4 m11778G > A mitochondrial DNA (mtDNA) mutation, which is pathognomonic for LHON.
\end{abstract}

Case presentation: Patient 1 was a 16-year-old boy diagnosed with bilateral JOAG and high myopia. His intraocular pressure (IOP) was poorly controlled with the use of full topical anti-glaucoma medications. His best-corrected visual acuity (BCVA) decreased gradually over 5 years. Fundoscopic examination revealed bilateral enlarged disc cupping of the optic nerves with sectorial excavation and reduction of the neural rim in the left eye. His visual field (VF) was characterized by bilateral progressive central scotoma. Pattern visual evoked potentials (VEPs) and pattern electroretinograms (ERGs) showed extinguished responses in both eyes. Because of the non-specific visual field findings and the optic neuropathy disclosed by the pattern VEPs and pattern ERGs, we arranged a genetic test for the patient, which revealed an m11778G > A mtDNA mutation. Patient 2, the younger brother of Patient 1, was a 15-year-old boy who had been diagnosed with bilateral JOAG in 2010. The BCVA of both eyes remained at 1.0 during the follow-up period. Fundoscopic examination revealed bilateral mildly paled optic disc with enlarged cupping and reduction of the neural rim. The pattern ERG revealed a decreased N95 amplitude bilaterally. The genetic test revealed an m11778G > A mtDNA mutation. Patient 3 was a 35-year-old man with bilateral JOAG. His BCVA decreased gradually over 10 years. Fundoscopic examination revealed paled optic disc with enlarged disc cupping and reduction of the neural rim in both eyes. The pattern ERG revealed a decreased N95 amplitude bilaterally. The genetic test revealed an m11778G > A mtDNA mutation.

Conclusions: This case series describes three patients with concomitant occurrence of JOAG and LHON. These two diseases may have a cumulative effect on oxidative stress and retinal ganglion cell death with the rapid deterioration of vision, which may occur during adolescence.

Keywords: Leber's hereditary optic neuropathy, Juvenile open-angle glaucoma, Mitochondria

\section{Background}

Leber's hereditary optic neuropathy (LHON) is a maternally inherited recessive disease caused by a mutation in the mtDNA. In 1858, Dr. Albrecht von Graefe proposed the first mitochondrial disease attributed to a point mutation. Dr. Theodore Leber reported 15 patients with this disease years later; the disease was therefore named after him [1,

\footnotetext{
* Correspondence: lanhsin.chuang@gmail.com

'Department of Ophthalmology, Chang-Gung Memorial Hospital, 222

Mai-Chin Rd, Keelung 204, Taiwan (Republic of China)

${ }^{3}$ College of Medicine, Chang Gung University, Taoyuan, Taiwan

Full list of author information is available at the end of the article
}

2]. The selective degeneration of retinal ganglion cells (RGCs), which are sensitive to mitochondrial dysfunction, leads to vision loss [3]. LHON develops mostly in young adult males with a mean age of onset between 18 years and 35 years. The affected individuals typically present unilateral acute/subacute, painless, and central/cecocentral visual loss. Six to 8 weeks later, the fellow eye becomes involved $[4,5]$. Abnormal cupping of the optic nerve head can be found by clinicians. The appearance in the atrophic stage of LHON is similar to that in glaucoma patients. In addition, an association between normal-tension glaucoma and LHON has also been described $[4,6]$. Although retinal ganglion cell

(c) The Author(s). 2018 Open Access This article is distributed under the terms of the Creative Commons Attribution 4.0 International License (http://creativecommons.org/licenses/by/4.0/), which permits unrestricted use, distribution, and 
death is evident in both LHON and glaucoma, the disease course and pathophysiology of these two diseases are different. A slow and progressive disease course and the presence of elevated intraocular pressure (IOP) are commonly seen in glaucoma patients, while an acute onset disease course and point mutations in mtDNA are seen in LHON. Few studies have demonstrated the simultaneous occurrence of these two diseases. In this case series, we describe the concomitant occurrence of juvenile open-angle glaucoma (JOAG) and LHON in 3 patients, 2 of whom are siblings.

This study has a retrospective design. The medical records of 3 patients who presented with JOAG and LHON were reviewed. Patient records were reviewed for demographic information, best-corrected visual acuity (BCVA) with the Snellen chart, IOP at disease onset, nadir and last follow-up clinic visit, visual field (VF), and gonioscopic, pachymetric, and fundoscopic examinations. Due to the atypical visual field defect pattern in these patients, electrophysiological testing and genetic testing were arranged and recorded as well. This study was approved by the Institutional Review Board of the Chang Gung Medical Foundation.

\section{Case presentation}

\section{Case 1}

A 16-year-old boy without systemic disease had come to our attention in October 2012 with a diagnosis of bilateral JOAG and high myopia $(-8.0 \mathrm{D})$. Although he was treated with dorzolamide $2 \%$, latanoprost $0.005 \%$, brimonidine $0.2 \% /$ timolol $0.5 \%$ fixed combination, and oral acetazolamide $500 \mathrm{mg} /$ day at another hospital, his IOP was approximately $25 \mathrm{mmHg}$ and was poorly controlled in both eyes by full medication. Several months before this visit, he had ceased treatment with anti-glaucoma medication. His BCVA was $20 / 20$ in both eyes in 2012, though it gradually deteriorated to $20 / 400$ in both eyes in 2017. Gonioscopy revealed a normal iridocorneal angle; pachymetric measurements were $611 \mu \mathrm{m}$ in the right eye and $614 \mu \mathrm{m}$ in the left eye. The axial length of the right eye was $27.56 \mathrm{~mm}$ and that of the left eye was $27.46 \mathrm{~mm}$. Fundoscopic examination revealed bilateral enlarged disc cupping of the optic nerves with sectorial excavation and reduction of the neural rim in the left eye (Fig. 1). Optical coherence tomography angiography (OCTA) revealed retinal nerve fiber layer (RNFL) thinning over the temporal upper and lower quadrants and nasal upper quadrant of the right eye and RNFL thinning at the temporal quadrant and nasal upper quadrant of the left eye (Fig. 2). The vascularity of the peripapillary capillaries was $43.6 \%$ in the right eye and $49.15 \%$ in the left eye. Both eyes revealed a decrease in the sectoral division of the temporal regions (Fig. 2). A VF of 30-2 Swedish interactive thresholding algorithm standard (30-2 SITA standard) was characterized by progressive central scotoma in both eyes (Fig. 3). Due to the presence of bilateral progressive central scotoma, further examinations were arranged. The electroretinogram (ERG) result was subnormal in both eyes, and there were more decreased amplitudes in the right eye than there were in the left eye. However, no obvious implicit time delay was noted. The pattern visual evoked potential (VEP) and pattern ERG showed extinguished responses in both eyes (Fig. 4). A brain MRI revealed an incidental finding of a $0.8 \mathrm{~mm}$ non-enhancing nodule in the pituitary gland. Furthermore, the genetic test revealed an ND4 m11778G > A mtDNA mutation, which is pathognomonic for LHON. High-dose ubidecarenone $(240 \mathrm{mg} /$ day) was prescribed by the neurologist. However, under high-dose ubidecarenone therapy, the patient's IOP was still poorly controlled and his visual acuity gradually decreased to less than 20/400 in both eyes after one year of ubidecarenone treatment.

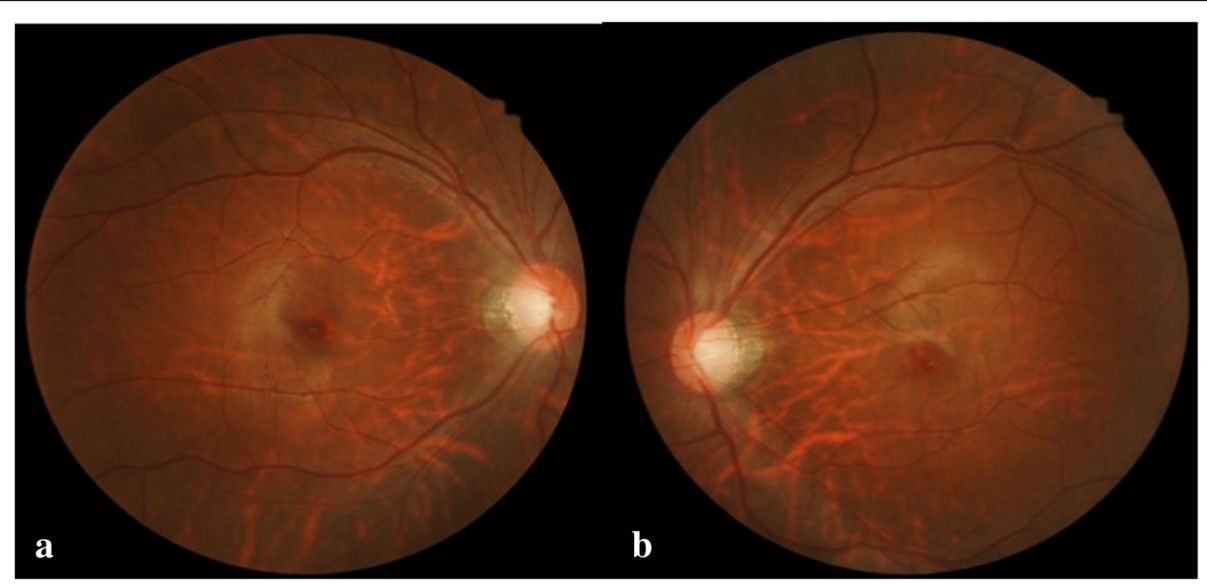

Fig. 1 Fundoscopic photographs of the right eye (a) and left eye (b) of Patient 1. The fundoscopic photographs of Patient 1 revealed bilateral enlarged disc cupping of the optic nerves with sectorial excavation and reduction of the neural rim in the left eye 


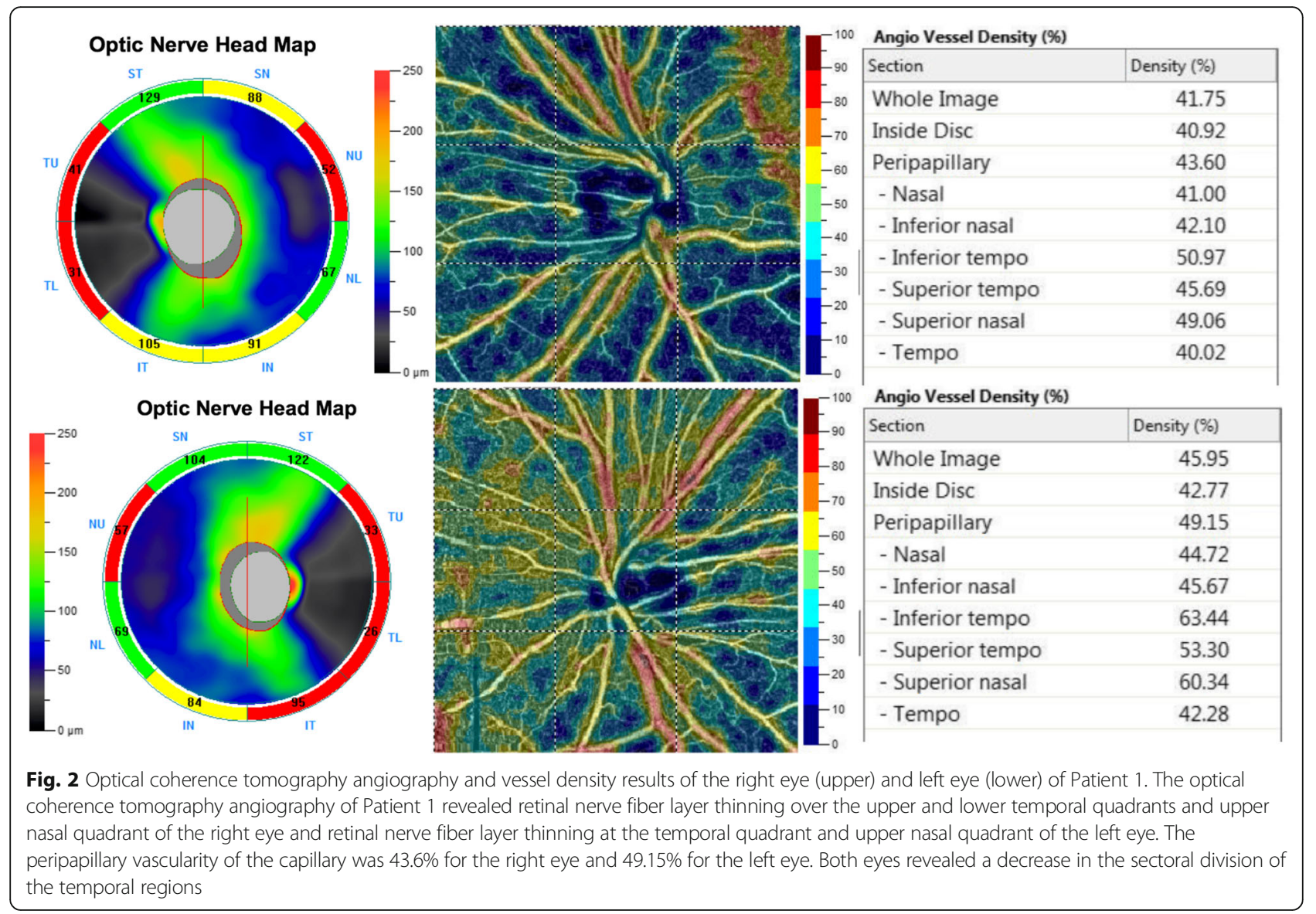

\section{Case 2}

A 15-year-old boy, the first younger brother of Patient 1 who was diagnosed with bilateral JOAG in 2010, attended our clinic in October 2012. He denied having systemic disease, but he had a family history of glaucoma and LHON (Fig. 5). After taking medication, including dorzolamide $2 \%$ /timolol $0.5 \%$ fixed combination, latanoprost $0.005 \%$, and brimonidine $0.15 \%$, IOP was controlled in both eyes. His BCVA of both eyes remained at 20/20 during the follow-up period. Gonioscopy revealed a normal iridocorneal angle, and the pachymetric measurements were $592 \mu \mathrm{m}$ in both eyes. Fundoscopic examination revealed bilateral mildly paled optic disc with enlarged cupping and reduction of the neural rim in both eyes (Fig. 6). OCTA revealed RNFL thinning at the nasal upper quadrant of the left eye (Fig. 7). The VF (30-2 SITA standard) was normal in both eyes during the follow-up period. The pattern VEP showed no delay, and the pattern ERG revealed decreased N95 amplitudes in both eyes (Fig. 8). The genetic test revealed an ND4

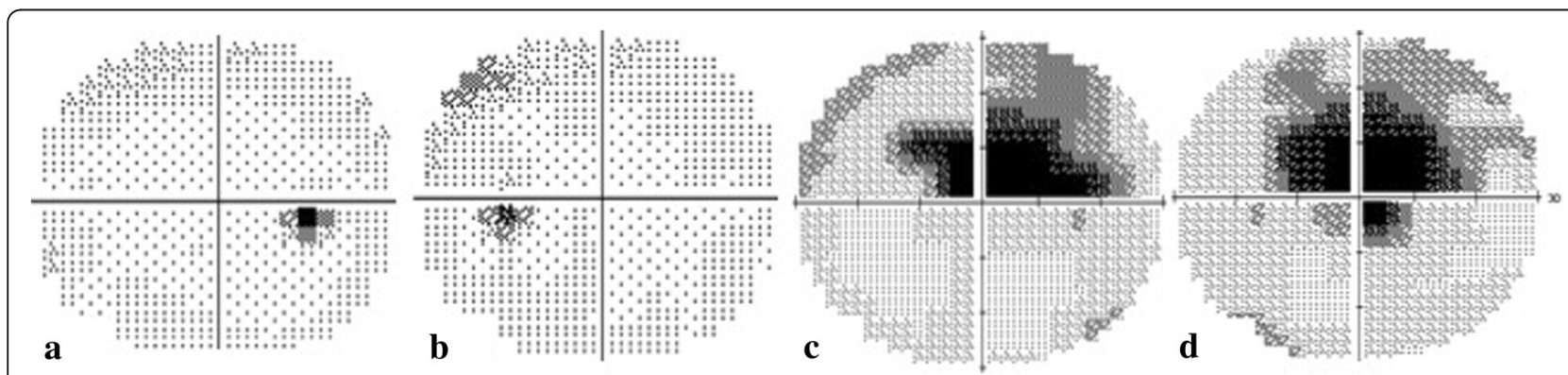

Fig. 3 The visual fields of the right eye (a) and left eye (b) of Patient 1 in 2013 and the visual fields of the right eye (c) and left eye (d) of Patient 1 in 2016The visual field (30-2 SITA standard) was characterized by bilateral progressive central scotoma in the eyes from 2013 to 2016 . ${ }^{*}$ SITA: Swedish interactive thresholding algorithm. 


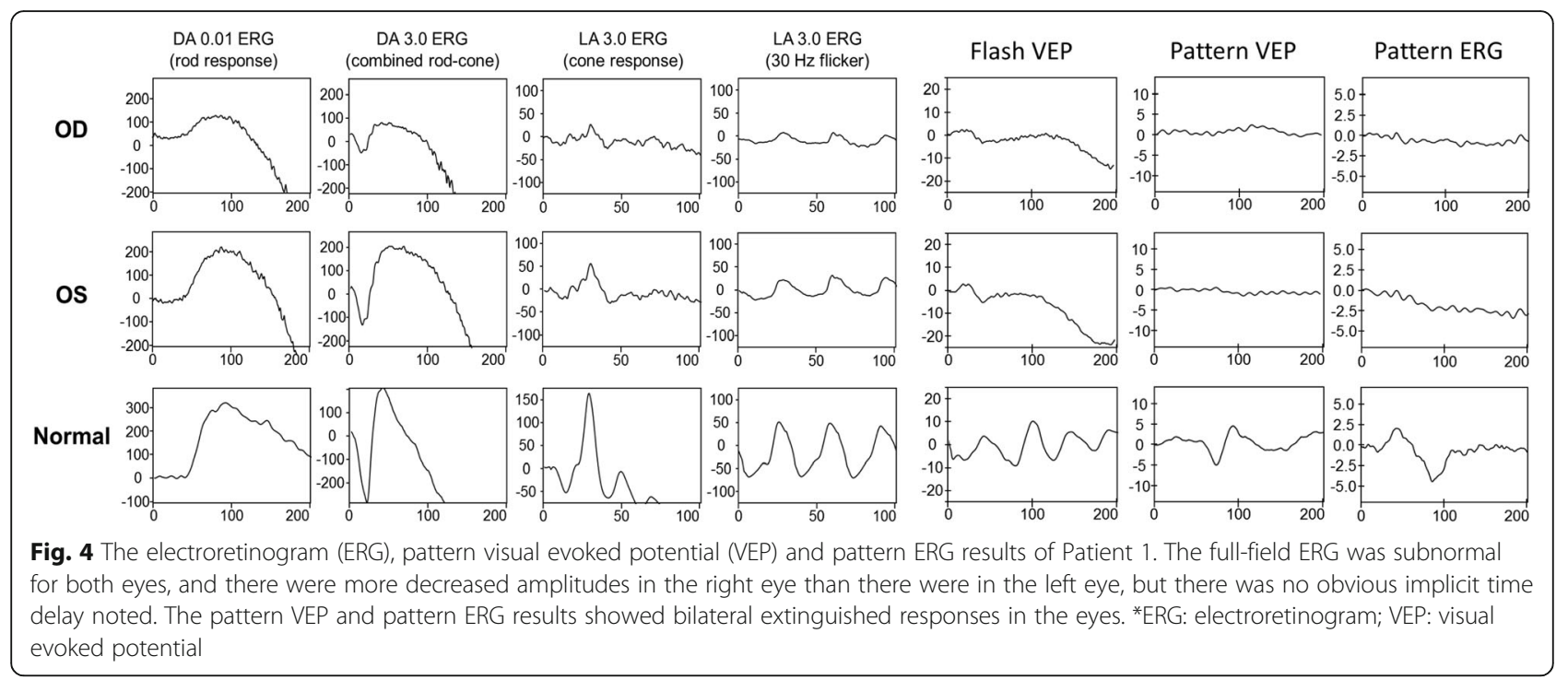

m11778G > A mtDNA mutation, which is pathognomonic for LHON. High-dose ubidecarenone $(240 \mathrm{mg} /$ day) was prescribed as well. During the course of high-dose ubidecarenone treatment, the patient's IOP, visual acuity, and visual field remain stable.

\section{Case 3}

A 35-year-old man without systemic disease first attended our clinic in August 2004 for bilateral JOAG. $\mathrm{He}$ denied having a family history of glaucoma, but his uncle had been diagnosed with LHON. When he was undergoing therapy with timolol $0.5 \%$, his IOP was approximately $20 \mathrm{mmHg}$ in both eyes. His BCVA gradually decreased from 20/200 in both eyes in 2006 to counting fingers at $25-30 \mathrm{~cm}$ in both eyes in 2016. Gonioscopy revealed a normal iridocorneal angle; pachymetric measurements were $561 \mu \mathrm{m}$ in the right eye and $563 \mu \mathrm{m}$ in the left eye. Fundoscopic examination revealed paled optic disc with enlarged disc cupping of the optic nerves with sectorial excavation and reduction of the neural rim in both eyes (Fig. 9). OCTA disclosed diffuse RNFL thinning and a decreased peripapillary vascularity in
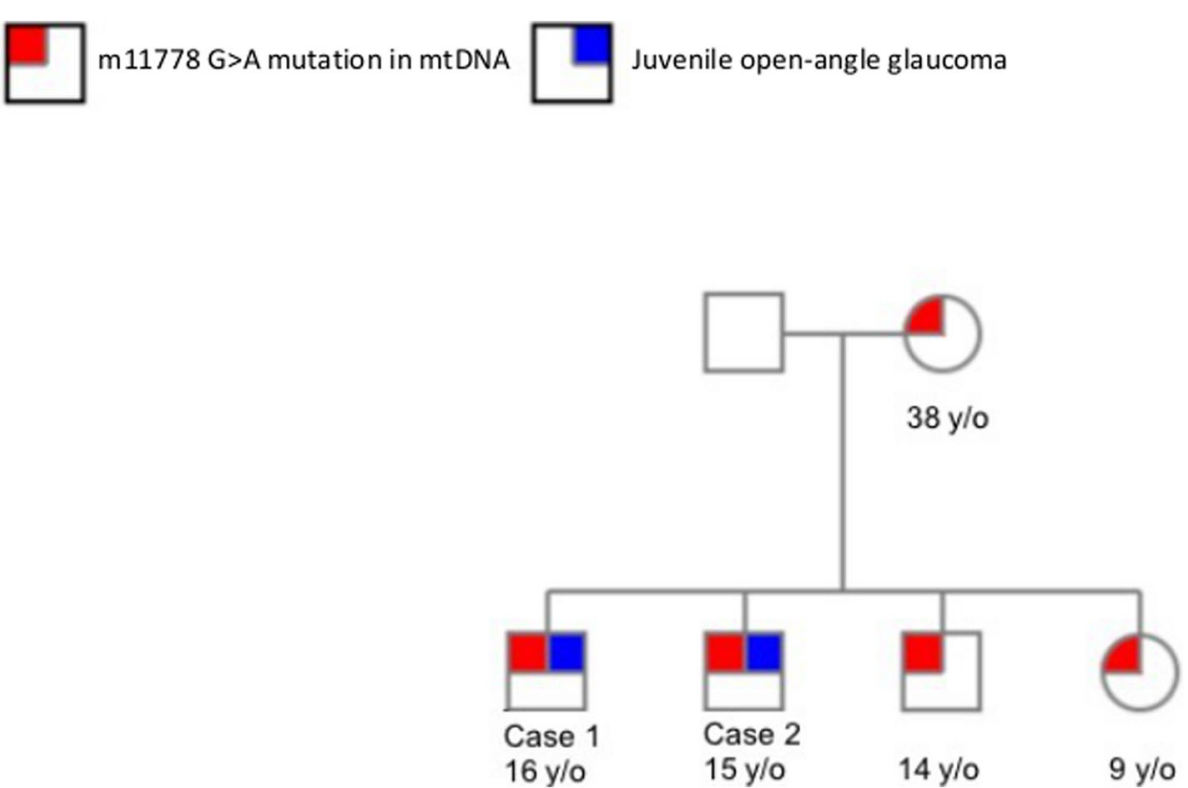

Fig. 5 The family pedigrees of Patient 1 and Patient 2. Patient 1 and Patient 2 were both diagnosed with JOAG and an mtDNA m11778 G>A mutation. The genetic tests revealed an mtDNA ND4 m11778G > A mutation in the younger brother, younger sister, and mother. ${ }^{*} m t D N A$ : mitochondrial DNA; y/o: year-old 


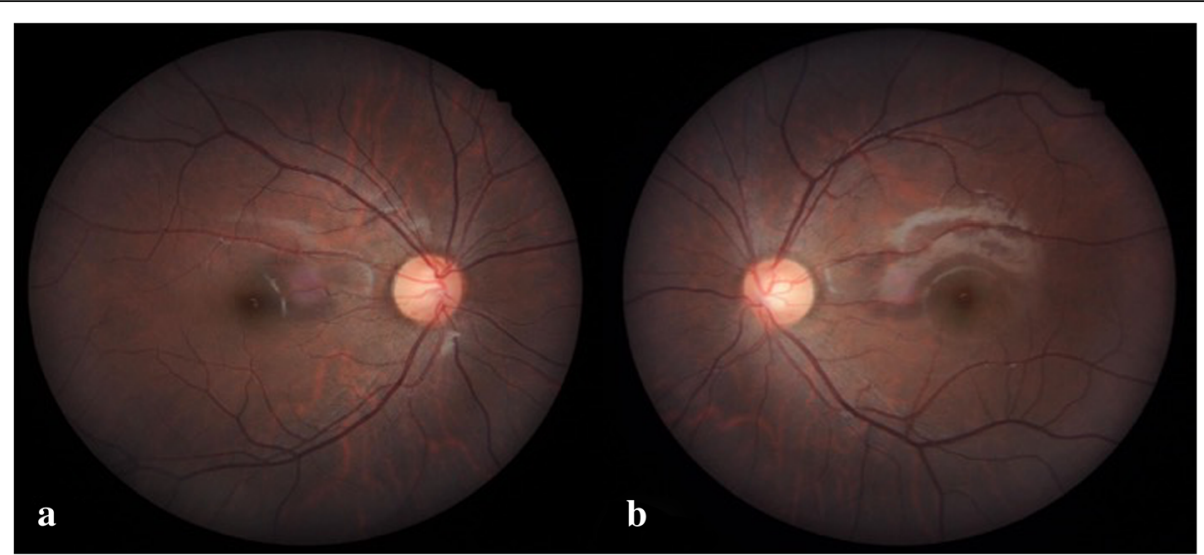

Fig. 6 Fundoscopic photographs of the right eye (a) and left eye (b) of Patient 2. Fundoscopic photographs of Patient 2 revealed bilateral mildly paled optic disc with enlarged cupping and bilateral reduction of the neural rim in the eyes

both eyes (Fig. 10). The VF (30-2 SITA standard) was characterized by progressive central scotoma in both eyes. The ERG was subnormal in both eyes, and the pattern ERG revealed decreased N95 amplitudes in both eyes (Fig. 11). The genetic test revealed an ND4 m11778G > A mtDNA mutation, which is pathognomonic for LHON.

\section{Discussion and conclusions}

This case series describes three patients with an ND4 m11778G > A mtDNA mutation who had the concomitant occurrence of JOAG and LHON. Among them, Patient 1 and Patient 2 are brothers. In 2013, Nucci et al. had described a woman with open-angle glaucoma progression that was associated with Leber's hereditary optic neuropathy (LHON). This patient also had the ND4 m11778G > A mtDNA mutation [7]. Approximately $90 \%$ of patients with LHON carry one of three mtDNA point mutations, which are located at the nucleotide positions 3460, 11,778, and 14,484 [8]. Among them, the most common point mutation, which accounts for $70 \%$ of all cases, is that at position 11,778 ,

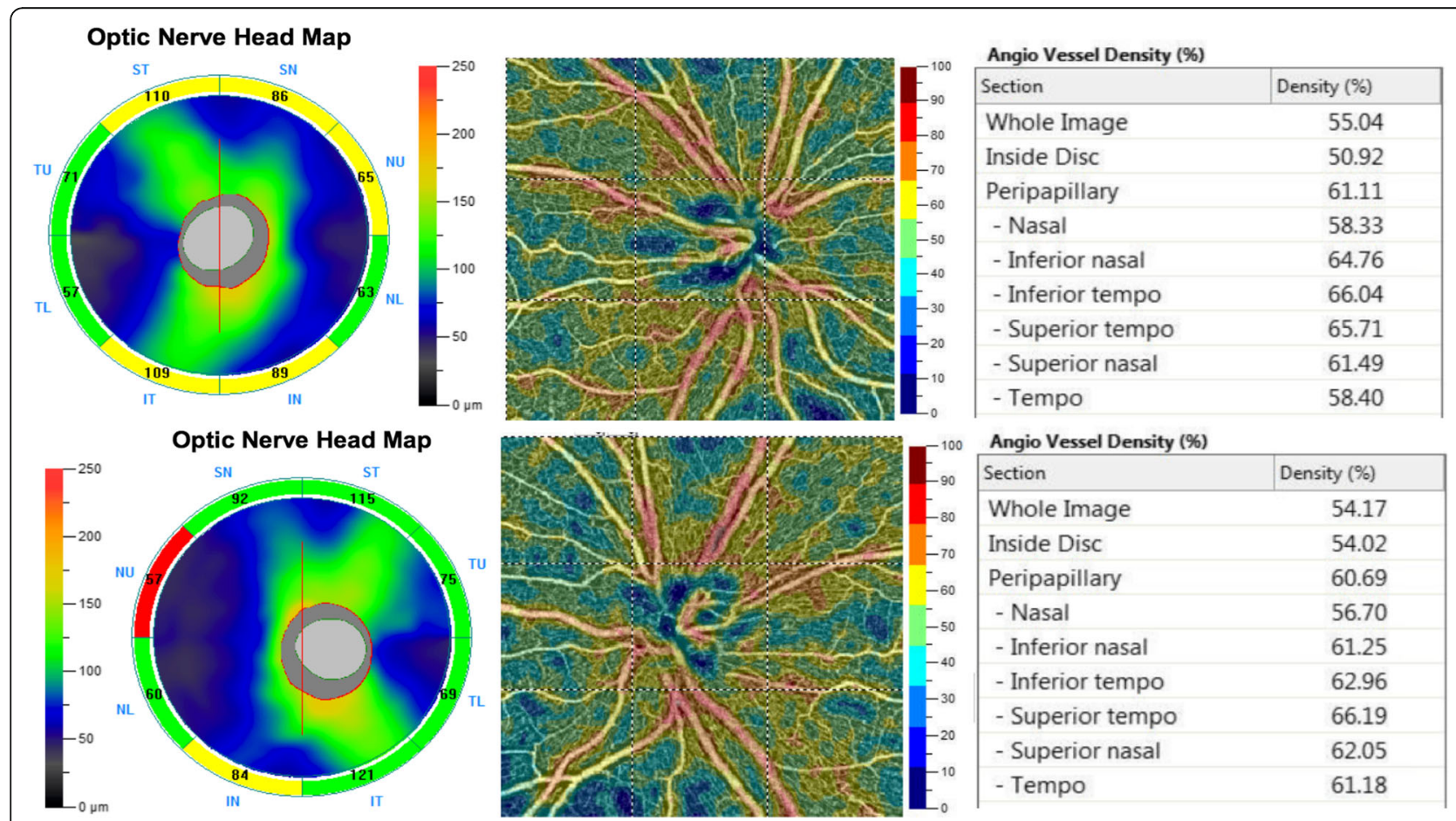

Fig. 7 Optical coherence tomography angiography and vessel density results of the right eye (upper) and left eye (lower) of Patient 2. Optical coherence tomography angiography of Patient 2 revealed retinal nerve fiber layer thinning at the upper nasal quadrant of the left eye 


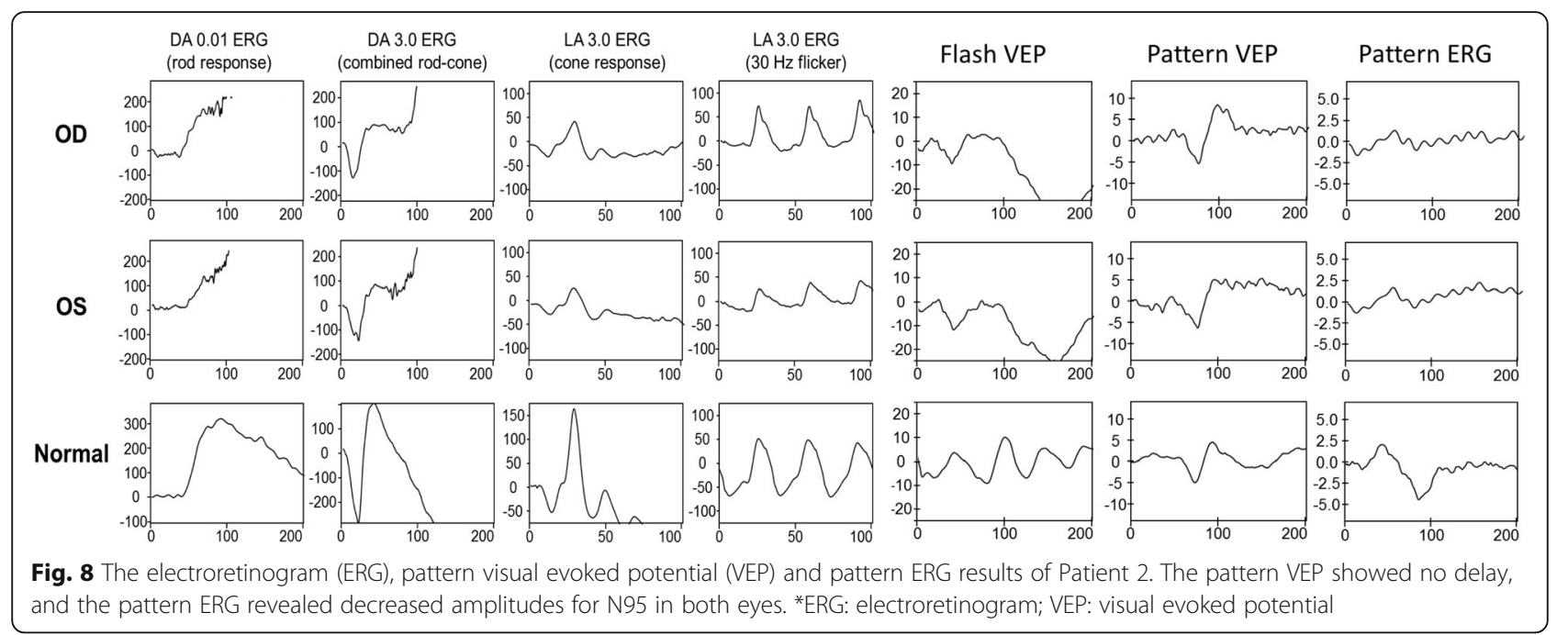

which is that identified in these cases [8]. The 14,484 and 3460 mutations account for approximately 14 and $13 \%$, respectively, of the total number of cases $[9,10]$. Previous studies have demonstrated that LHON predominantly affects males (80-90\% of cases) [8]. In addition, $60 \%$ of LHON patients are aware that they have a family history of LHON, although $40 \%$ of them deny having a known family history [11].

The onset of symptoms in LHON typically occurs at young ages, but there have been few reports of symptom onset from 2 years to 87 years of age $[8,12]$. The clinical presentation of LHON is acute or sub-acute, unilateral, and painless visual loss followed by the involvement of the other eye within 1-2 months. Visual acuity is typically worse than $20 / 200$ or light perception [13, 14]. Visual field defects are typically central or cecocentral scotoma, and dyschromatopsia is often present early in the disease progression [15]. Acute funduscopic abnormalities seen in LHON include swelling of the nerve fiber layer around the disc, hyperemia of the optic nerve head, circumpapillary telangiectasia, tortuous engorged retinal vessels, and the absence of disc leakage on fluorescein angiography. Following the acute stage of the disease, the tortuosity of the retinal vessels improves, the telangiectatic vessels resolve, and optic nerve pallor (without swelling) develops [16, 17]. The funduscopic findings of the patients in the current case series revealed that they were all in the chronic stage and had a pallor optic disc and enlarged disc cupping.

Peripapillary retinal nerve fiber layer (RNFL) and vessel density changes seen in LHON can be characterized and quantified by OCTA. Impaired mitochondrial function in LHON leads to early axonal swelling of the RGCs. Previous studies has observed that, in OCTA, the

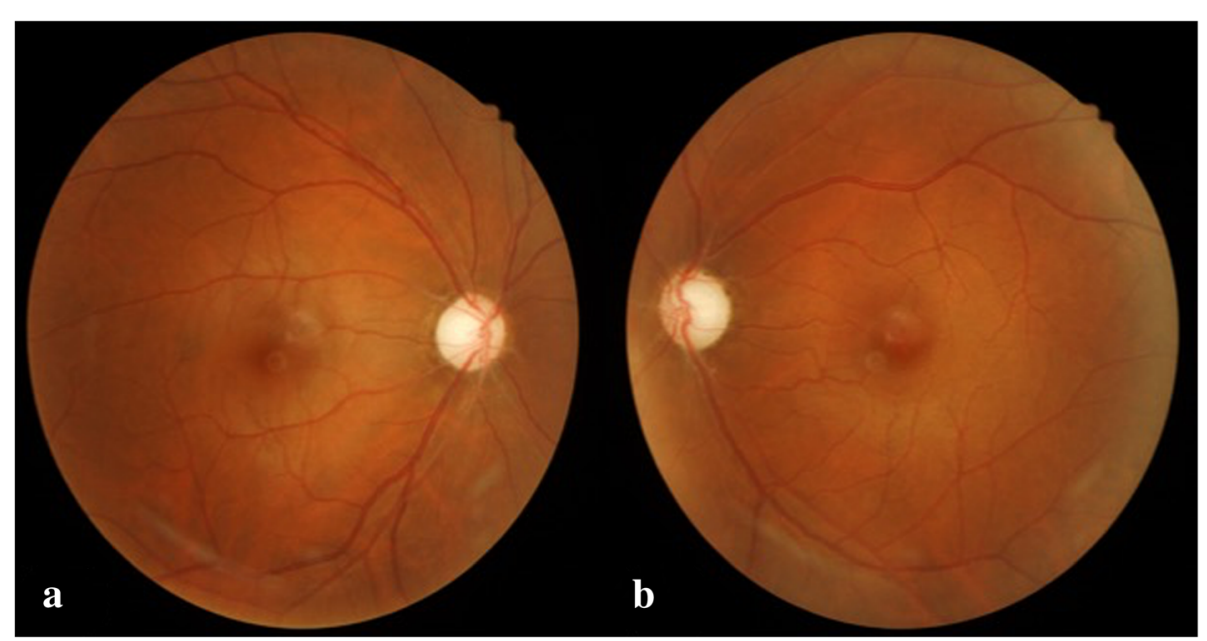

Fig. 9 Fundoscopic photographs of the right eye (a) and left eye (b) of Patient 3. Fundoscopic photographs of Patient 3 revealed paled optic disc with enlarged disc cupping of the optic nerves and sectorial excavation and reduction of the neural rim in both eyes 


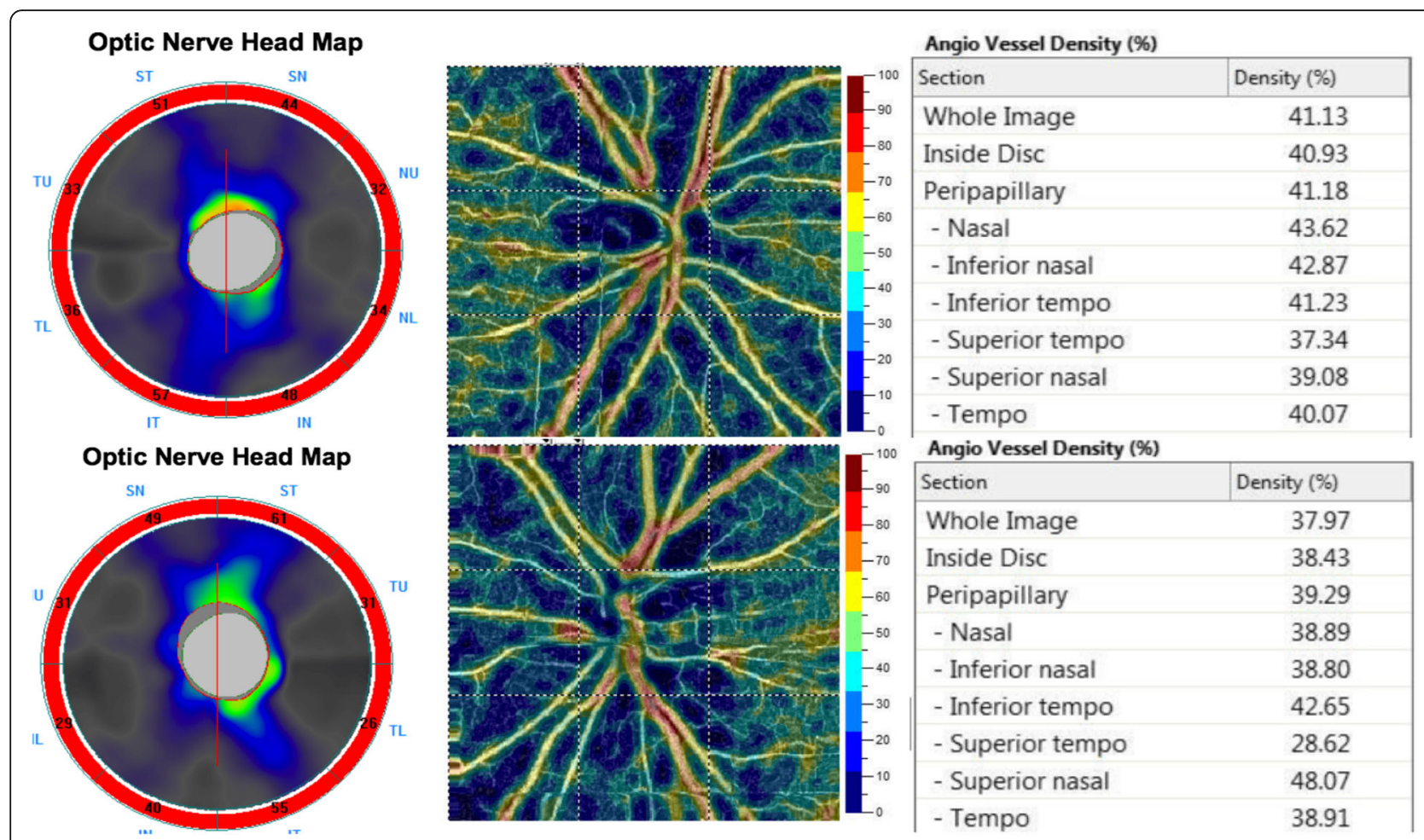

Fig. 10 Optical coherence tomography angiography and vessel density results of the right eye (upper) and left eye (lower) of Patient 3. Optical coherence tomography angiography of Patient 3 disclosed diffuse RNFL thinning and a bilateral decrease in the peripapillary vascularity in the eyes

RNFL thickens first in the temporal and inferior quadrants, and then in the superior and nasal quadrants in the acute phase [18]. A few months later, the thickness of RNFL decreased during the chronic phase [19], which was fully demonstrated in the OCTA findings of Patient 1 and Patient 3 in the current study. Additionally, changes in the peripapillary vascularity of the capillaries were also observed in our cases. The sectoral division changes of the RNFL and peripapillary vascularity of the capillaries in our cases were not typical changes seen in primary open-angle glaucoma patients.

Visual evoked potentials (VEPs) reflect optic nerve fiber degeneration; pattern ERGs detect RGC loss and are often abnormal in patients with LHON. Findings for concomitance are different from that for typical glaucoma or LHON. In Patient 1, the VEP and pattern ERG

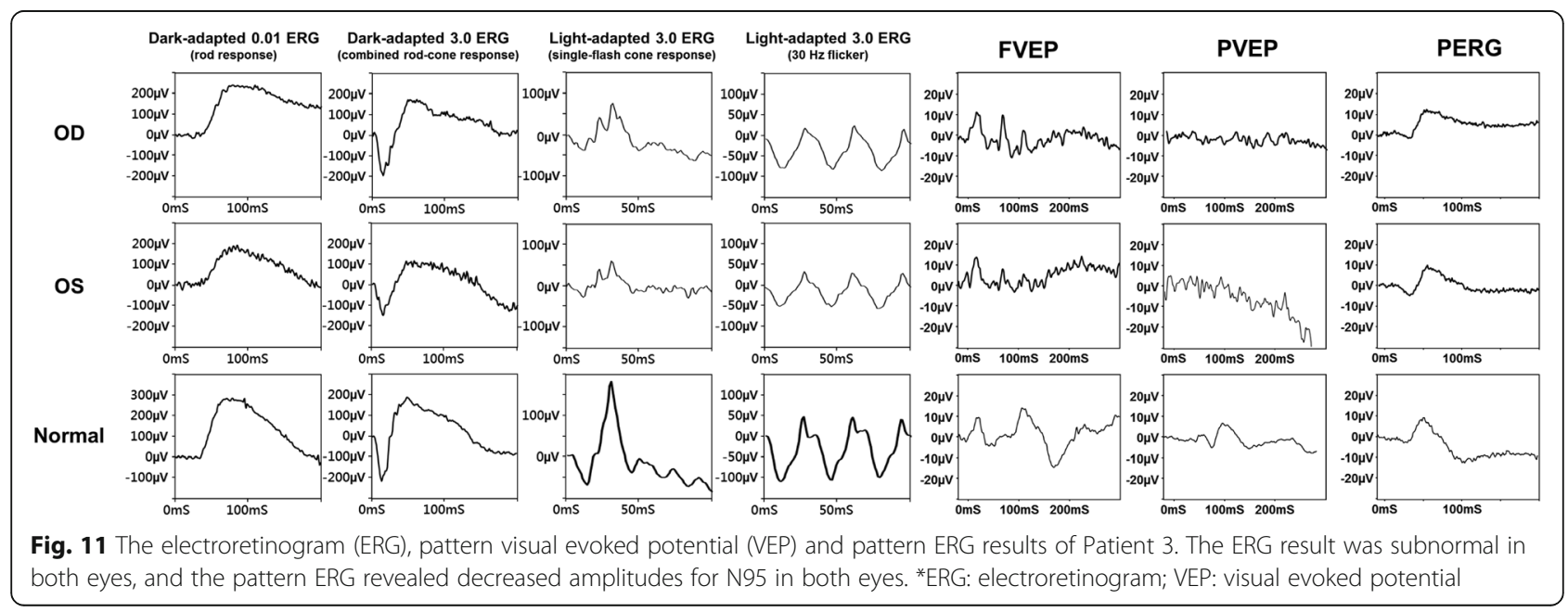


both showed extinguished responses in both eyes. The pattern ERGs of Patient 2 and Patient 3 revealed decreased N95 amplitudes in both eyes. Salomao et al. reported that in a Brazilian family the pattern-reversal VEP showed prolonged latencies, decreased amplitudes, or extinguished responses in three of the affected members [20]. Dorfman et al. presented two brothers with LHON, and the earliest detected VEP abnormalities were abnormal pattern and increase latency. In addition, the VEP latency further prolonged with disease progression [21]. Ziccardi et al. presented patients who also had an prolonged VEP latency, decreased VEP amplitude, and a decreased ERG amplitude in N50-N95 [22].

Magnetic resonance imaging (MRI) finding in LHON patients is usually normal [23]. However, there are reports of patients who had an increased signal in the optic nerve on T2-weighted fast spin echo and short-time inversion recovery sequences in the chronic atrophic stage [24, 25]. Optic nerve enhancement on post-contrast MRI images has been demonstrated in some case reports. That suggests that the LHON may have an inflammatory component in its pathogenesis [26].

Affected LHON patients typically have poor visual prognosis. Permanent vision loss was observed in most affected individuals, and only few studies have reported spontaneous visual recovery [27]. The partial visual recovery rate of patients with the 14,484 mutation was $37-58 \%$. Individuals with the 3460 mutation have an approximately $20 \%$ partial recovery rate. The $11,778 \mathrm{mu}-$ tation is associated with the lowest recovery rate, with a partial recovery rate of $4 \%[5,11,28,29]$.

Recent studies in LHON cybrids have shown that the mtDNA mutations reduce the rate of respiration and oxygen consumption with increased superoxide production [30]. Since ATP production is an essential task of mitochondria, they play vital roles for the cell, including in the detoxification of reactive oxygen species (ROS), iron metabolism, amino acid biosynthesis, fatty acid oxidation, and cellular apoptosis. As highly ATP requiring tissue, the RGCs are sensitive to metabolic insult from mitochondrial dysfunction in LHON [3]. On the other hand, Sundaresan observed that $50 \%$ of patients with POAG have pathogenic mtDNA mutations, which was demonstrated by massive parallel sequencing [31]. Mitochondrial dysfunction can lead to the accumulation of ROS, which may affect the cellularity of the trabecular meshwork and impair aqueous drainage, leading to an elevated IOP [32, 33]. In previous studies, the lamina cribrosa cells from glaucoma donors were shown to have higher levels of ROS and compromised anti-oxidant potential compared with normal donors, suggesting that mitochondrial dysfunction and accumulation of oxidative stress are important in the pathogenesis of POAG [32, 34]. Additionally, Nucci et al. reported an atypical LHON (late adult female) and hypothesize that glaucoma had a superimposed cumulative effect on the oxidative stress in LHON patients, causing the RGCs damage and leading to the clinical manifestations of LHON [7].

In conclusion, this case series describes the concomitant occurrence of JOAG and LHON. Glaucoma may have cumulative effect on oxidative stress and RGCs death in LHON patients, leading to the rapid progression of visual deterioration, which may occur during adolescence with untypical findings in functional examinations.

\section{Abbreviations \\ BCVA: Best-corrected visual acuity; ERGs: Electroretinograms; IOP: Intraocular pressure; JOAG: Juvenile open-angle glaucoma; LHON: Leber's hereditary optic neuropathy; MRI: Magnetic resonance imaging; mtDNA: Mitochondrial DNA; OCTA: Optical coherence tomography angiography; RGCs: Retinal ganglion cells; RNFL: Retinal nerve fiber layer; ROS: Reactive oxygen species; VEPS: Visual evoked potentials; VF: Visual field}

\section{Acknowledgements}

Not applicable.

Funding

Not applicable.

\section{Availability of data and materials}

The datasets used and/or analyzed during the current study are available from the corresponding author on reasonable request.

\section{Authors' contributions}

LHC conceived of the idea and provided the cases. YHL collected data and completed the manuscript. NKW performed the VEPS and ERGs examination and helped in interpretation. LY and CCL supervised the findings of this work. All authors discussed the results of the three cases presented in this case series and have read and approved the manuscript.

Ethics approval and consent to participate

This study was approved by the Institutional Review Board of Chang Gung Medical Foundation. IRB No.: 201700707B0.

Consent for publication

Consent to publish has been obtained from the patients or their parents.

\section{Competing interests}

The authors declare that they have no competing interests.

\section{Publisher's Note}

Springer Nature remains neutral with regard to jurisdictional claims in published maps and institutional affiliations.

\section{Author details}

${ }^{1}$ Department of Ophthalmology, Chang-Gung Memorial Hospital, 222 Mai-Chin Rd, Keelung 204, Taiwan (Republic of China). ${ }^{2}$ Department of Ophthalmology, Chang-Gung Memorial Hospital, Linkou, Taiwan. ${ }^{3}$ College of Medicine, Chang Gung University, Taoyuan, Taiwan.

Received: 8 February 2018 Accepted: 29 November 2018

Published online: 17 December 2018

\section{References}

1. Wallace DC. A new manifestation of Leber's disease and a new explanation for the agency responsible for its unusual pattern of inheritance. Brain. 1970; 93(1):121-32. 
2. Wallace DC, Singh G, Lott MT, Hodge JA, Schurr TG, Lezza AM, et al. Mitochondrial DNA mutation associated with Leber's hereditary optic neuropathy. Science. 1988;242(4884):1427-30.

3. Meyerson C, Van Stavern G, McClelland C. Leber hereditary optic neuropathy: current perspectives. Clin Ophthalmol. 2015;9:1165-76.

4. Yu-Wai-Man P, Turnbull DM, Chinnery PF. Leber hereditary optic neuropathy. J Med Genet. 2002;39(3):162-9.

5. Yu-Wai-Man P, Griffiths PG, Hudson G, Chinnery PF. Inherited mitochondrial optic neuropathies. J Med Genet. 2009;46(3):145-58.

6. Mashima Y, Kimura I, Yamamoto Y, Ohde H, Ohtake Y, Tanino T, et al. Optic disc excavation in the atrophic stage of Leber's hereditary optic neuropathy: comparison with normal tension glaucoma. Graefes Arch Clin Exp Ophthalmol. 2003;241(2):75-80.

7. Nucci C, Martucci A, Mancino R, Cerulli L. Glaucoma progression associated with Leber's hereditary optic neuropathy. Int Ophthalmol. 2013;33(1):75-7.

8. Newman NJ. Hereditary optic neuropathies: from the mitochondria to the optic nerve. Am J Ophthalmol. 2005;140(3):517-23.

9. Yu-Wai-Man P, Griffiths PG, Chinnery PF. Mitochondrial optic neuropathies disease mechanisms and therapeutic strategies. Prog Retin Eye Res. 2011; 30(2):81-114.

10. Fraser JA, Biousse V, Newman NJ. The neuro-ophthalmology of mitochondrial disease. Surv Ophthalmol. 2010;55(4):299-334.

11. Yu-Wai-Man P, Griffiths PG, Howell N, Turnbull DM, Chinnery PF. The epidemiology of Leber hereditary optic neuropathy in the north east of England. Am J Hum Genet. 2016;98(6):1271.

12. Giraudet $S$, Lamirel C, Amati-Bonneau P, Reynier P, Bonneau D, Milea D, et al. Never too old to harbour a young man's disease? Br J Ophthalmol. 2011; 95(6):896-7.

13. Riordan-Eva P, Sanders MD, Govan GG, Sweeney MG, Da Costa J, Harding AE. The clinical features of Leber's hereditary optic neuropathy defined by the presence of a pathogenic mitochondrial DNA mutation. Brain. 1995; 118(Pt 2):319-37.

14. Newman NJ, Lott MT, Wallace DC. The clinical characteristics of pedigrees of Leber's hereditary optic neuropathy with the 11778 mutation. Am J Ophthalmol. 1991;111(6):750-62.

15. Nikoskelainen EK, Huoponen K, Juvonen V, Lamminen T, Nummelin K, Savontaus ML. Ophthalmologic findings in Leber hereditary optic neuropathy, with special reference to mtDNA mutations. Ophthalmology. 1996;103(3):504-14.

16. Mizoguchi A, Hashimoto $Y$, Shinmei $Y$, Nozaki M, Ishijima K, Tagawa Y, et al. Macular thickness changes in a patient with Leber's hereditary optic neuropathy. BMC Ophthalmol. 2015;15:27.

17. Smith JL, Hoyt WF, Susac JO. Ocular fundus in acute Leber optic neuropathy. Arch Ophthalmol. 1973;90(5):349-54.

18. Barboni P, Carbonelli M, Savini G, Ramos Cdo V, Carta A, Berezovsky A, et al. Natural history of Leber's hereditary optic neuropathy: Iongitudinal analysis of the retinal nerve fiber layer by optical coherence tomography. Ophthalmology. 2010;117(3):623-7.

19. Barboni P, Savini G, Valentino ML, Montagna P, Cortelli P, De Negri AM, et al. Retinal nerve fiber layer evaluation by optical coherence tomography in Leber's hereditary optic neuropathy. Ophthalmology. 2005;112(1):120-6.

20. Salomao SR, Berezovsky A, Andrade RE, Belfort R Jr, Carelli V, Sadun AA. Visual electrophysiologic findings in patients from an extensive Brazilian family with Leber's hereditary optic neuropathy. Doc Ophthalmol. 2004; 108(2):147-55.

21. Dorfman LJ, Nikoskelainen E, Rosenthal AR, Sogg RL. Visual evoked potentials in Leber's hereditary optic neuropathy. Ann Neurol. 1977; 1(6):565-8.

22. Ziccardi L, Sadun F, De Negri AM, Barboni P, Savini G, Borrelli E, et al. Retina function and neural conduction along the visual pathways in affected and unaffected carriers with Leber's hereditary optic neuropathy. Invest Ophthalmol Vis Sci. 2013;54(10):6893-901.

23. Newman NJ. Leber's hereditary optic neuropathy. New genetic considerations. Arch Neurol. 1993:50(5):540-8.

24. Dotti MT, Caputo N, Signorini E, Federico A. Magnetic resonance imaging findings in Leber's hereditary optic neuropathy. Eur Neurol. 1992;32(1):17-9.

25. Kermode AG, Moseley IF, Kendall BE, Miller DH, MacManus DG, McDonald WI. Magnetic resonance imaging in Leber's optic neuropathy. J Neurol Neurosurg Psychiatry. 1989;52(5):671-4.

26. Furuki M, Ohkubo T, Ota K, Ishikawa K, Yokota T, Mizusawa H. Optic nerve swelling and gadolinium contrast enhancement on magnetic resonance imaging in the subacute stage of Leber's hereditary optic neuropathy: a case report. Rinsho Shinkeigaku. 2012;52(2):102-5.

27. Kirkman MA, Korsten A, Leonhardt M, Dimitriadis K, De Coo IF, Klopstock T, et al. Quality of life in patients with leber hereditary optic neuropathy. Invest Ophthalmol Vis Sci. 2009;50(7):3112-5.

28. Harding AE, Sweeney MG, Govan GG, Riordan-Eva P. Pedigree analysis in Leber hereditary optic neuropathy families with a pathogenic mtDNA mutation. Am J Hum Genet. 1995;57(1):77-86.

29. Johns DR, Heher KL, Miller NR, Smith KH. Leber's hereditary optic neuropathy. Clinical manifestations of the 14484 mutation. Arch Ophthalmol. 1993;111(4):495-8.

30. Vergani L, Martinuzzi A, Carelli V, Cortelli P, Montagna P, Schievano G, et al. MtDNA mutations associated with Leber's hereditary optic neuropathy: studies on cytoplasmic hybrid (cybrid) cells. Biochem Biophys Res Commun. 1995;210(3):880-8.

31. Sundaresan P, Simpson DA, Sambare C, Duffy S, Lechner J, Dastane A, et al. Whole-mitochondrial genome sequencing in primary open-angle glaucoma using massively parallel sequencing identifies novel and known pathogenic variants. Genet Med. 2015;17(4):279-84.

32. Kamel K, Farrell M, O'Brien C. Mitochondrial dysfunction in ocular disease: focus on glaucoma. Mitochondrion. 2017;35:44-53.

33. Yuki K, Tsubota K. Increased urinary 8-hydroxy-2'-deoxyguanosine (8-OHdG)/ creatinine level is associated with the progression of normal-tension glaucoma. Curr Eye Res. 2013;38(9):983-8.

34. McElnea EM, Quill B, Docherty NG, Irnaten M, Siah WF, Clark AF, et al. Oxidative stress, mitochondrial dysfunction and calcium overload in human lamina cribrosa cells from glaucoma donors. Mol Vis. 2011;17:1182-91.

\section{Ready to submit your research? Choose BMC and benefit from:}

- fast, convenient online submission

- thorough peer review by experienced researchers in your field

- rapid publication on acceptance

- support for research data, including large and complex data types

- gold Open Access which fosters wider collaboration and increased citations

- maximum visibility for your research: over $100 \mathrm{M}$ website views per year

At $\mathrm{BMC}$, research is always in progress.

Learn more biomedcentral.com/submissions 